\title{
Patient-Support Program in Diabetes Care During the Covid-19 Pandemic: An Italian Multicentric Experience
}

\author{
Annalisa Natalicchio (D) \\ Camilla Sculco ${ }^{2}$ \\ Gianni Belletti ${ }^{2}$ \\ Martina Fontanelli ${ }^{2}$ \\ Carlotta Galeone ${ }^{3}$ \\ Antonio Carlo Bossi (iD) \\ 'Department of Emergency and Organ \\ Transplantation, Section of Internal \\ Medicine, Endocrinology, Andrology and \\ Metabolic Diseases, University of Bari \\ Aldo Moro, Bari, Italy; ${ }^{2}$ Healthcare \\ Network Partners Italy, Bologna, Italy; \\ ${ }^{3}$ Biostatistics \& Outcome Research, \\ Statinfo, Briosco (MB), Italy; ${ }^{4}$ Humanitas \\ Gavazzeni Diabetes Centre, Bergamo, \\ Italy
}

Purpose: Telephone coaching and health apps are effective means to support subjects with diabetes. Patient support programs (PSP) on type 2 diabetes are scanty, and none has been conducted in Italy. In a pilot phase, conducted during the COVID-19 pandemic, we aimed to examine the feasibility and acceptance of such program.

Methods: The "BE THere for diabetes CARE" (BETHCARE) project is a real-world PSP conducted through telephone and digital coaching system to provide educational and emotional support to Italian adults with diabetes receiving long-acting basal insulin degludec. This pilot phase was conducted in 11 centres that enrolled a total of 63 patients $(89 \%$ with type-2 diabetes). Counselors contacted patients to define a set of emotional, physical and nutritional targets, and monitoring calls were performed on a monthly basis. Data were collected on socio-demographic and anthropometric characteristics, selected clinical information, quality of life, achievement of targets and patient satisfaction.

Results: Fifty-eight subjects $(92 \%)$ chose to participate by telephone and $5(8 \%)$ by mobile app. Most participants (ie, $\geq 80 \%$ ) evaluated counselors' calls "useful/very useful", duration of calls "adequate/adequately long", were satisfied with the educational pathway and declared to be more confident in diabetes management after the program. About half of participants were confident to maintain their targets after the PSP. Achievement of nutritional targets improved during counseling, from a mean score of 1.56 at week 1 to 1.88 at week 16 $(\mathrm{p}$-value $=0.03)$. No significant variations in the achievement of emotional and physical targets emerged. Mean patients weight decreased from $84.9 \mathrm{~kg}$ (week 1) to $84.3 \mathrm{~kg}$ (week 4) and then levelled off ( $84.2 \mathrm{~kg}$, week 16).

Conclusion: This project demonstrated the feasibility and patient appreciation of a PSP in diabetes care, which is particularly important for a chronic disease of the elderly and during a pandemic period when face-to-face counseling is problematic.

Keywords: diabetes, patient support programs, real-world

\section{Introduction}

Diabetes is a considerable global chronic illness burden in ageing societies and is associated with severe long-term complications. Indeed, it is among the ten most important drivers of increasing burden of disease during the last thirty years, with a major increase in the number of disability-adjusted life-years related to diabetes, particularly in older adults. ${ }^{1}$

The number of diagnosed cases of diabetes is projected to increase substantially in the next decades. ${ }^{2}$ Consequently, the global health expenditure for patients with diabetes is expected to rise. ${ }^{3,4}$ Nonetheless, some health behaviors, as well as
Correspondence: Camilla Sculco

Email c.sculco@hnpgroup.eu 
adequate self-management, may positively affect both the progression of existing chronic conditions, including diabetes, and their impact on the quality of life of patients. Self-management support may improve both self-efficacy and some self-management behaviors. ${ }^{5}$ NICE guidelines recommend offering structured education to adults with diabetes and/or their family members or caregivers. ${ }^{6}$ Any structured education program for adults with diabetes should be evidence-based and follow a theory-driven structured curriculum. It is important to suit the needs of patients and take into account attitudes, beliefs, knowledge and skills to self-manage diabetes.

Telephone coaching was shown to be an effective means of supporting people with chronic diseases to manage their own health, providing health knowledge and education. ${ }^{7}$ A randomized controlled trial (RCT) demonstrated the efficacy of telephone support in diabetes management. ${ }^{8}$ Besides, telephone coaching interventions may be a cost-effective strategy to support diabetic patients. $^{9}$ The available evidence on the effectiveness of use of mobile health applications in Real-World diabetes programs is, on the other hand, still limited. ${ }^{10}$

To our knowledge, no patient support programs (PSP) on diabetes have been conducted to date in Italy. This pilot phase - conducted during the COVID-19 pandemic, that affected diabetic patients more severely ${ }^{11}$ - is aimed to examine the feasibility and acceptance of such program. We would highlight the massive impact of pandemic first wave in Italy, and the subsequent shortage of in-person specialists' visit in the Diabetes Centers located all over our Country.

\section{Materials and Methods}

The "BE THere for diabetes CARE" (BETHCARE) project is a PSP conducted through telephone and digital coaching system in subjects with diabetes receiving longacting basal insulin degludec. Its main aims are to provide educational and emotional support to Italian adults with diabetes (mainly type 2), to increase their awareness of this chronic disease and, ultimately, to improve their diet, lifestyle and overall management of diabetes. All data collected were fully anonymized. A multidisciplinary Scientific Board organized by Healthcare Network Partners Italy approved the PSP before starting the program (date: 19th November 2019) and the informed consent that was obtained from participants prior to program commencement. The project was conducted in accordance with the Declaration of Helsinki.
This pilot phase was conducted in 11 centers that enrolled a total of 63 patients. Inclusion criteria of the program are presence of diabetes and treatment with longacting basal insulin degludec, yet to be started or already ongoing.

The scheme of the PSP is shown in Figure 1. Diabetologists and endocrinologists involved in the program presented the project to the patients. Those interested to participate registered to the PSP according to their preferred method of participation, either through the contact center of the program or via a mobile application. At this stage, they were questioned to identify their profile and to collect data on socio-demographic characteristics, anthropometric factors, selected clinical information (eg, type and duration of diabetes, HbA1c, duration of insulin treatment, severity of diabetes during previous 12 months, etc), and quality of life, including a five-item Problem Areas in Diabetes Scale (PAID-5). Subsequently, within 7 days, counselors called the patients for the first time to share their profile and define the targets: emotional, physical (eg, increase walking times, taking the stairs, achieve a certain duration of physical activity per week, etc.) and nutritional (eg, increase fruit and vegetables consumption, avoid soft drinks, improve breakfast composition, eat whole- instead of refined-grains, etc.). Follow-up information was collected on body weight and through dietary and glycemic diaries. Monitoring calls were performed on a monthly basis to evaluate the achievement of patient targets and, if needed, to agree changes in the targets. At the end of the program, final data were collected on achievement of targets, changes in quality of life scores and on several aspects related to patient satisfaction with the program, such as evaluations of the clarity and kindness of the counselor, of the number, duration and usefulness of counselor calls, of the educational materials and diaries of the program, as well as on patient feelings on confidence to manage the disease and maintain lifestyle targets after the end of the counseling period.

\section{Statistical Methods}

Descriptive analyses were conducted by tabulating frequencies and percentages for categorical variables and mean, median values, standard deviations (SD) and interquartile ranges (IQR) for continuous variables. Achievement of nutritional, physical and emotional targets was registered using a scale ranging from 0 (target not achieved at all) to 3 points (target fully achieved). Comparisons between values at week 16 and at the start 
A diabetologist or endocrinologist presents the BETHCARE PSP to a patients treated with Tresiba, providing an explanatory leaflet

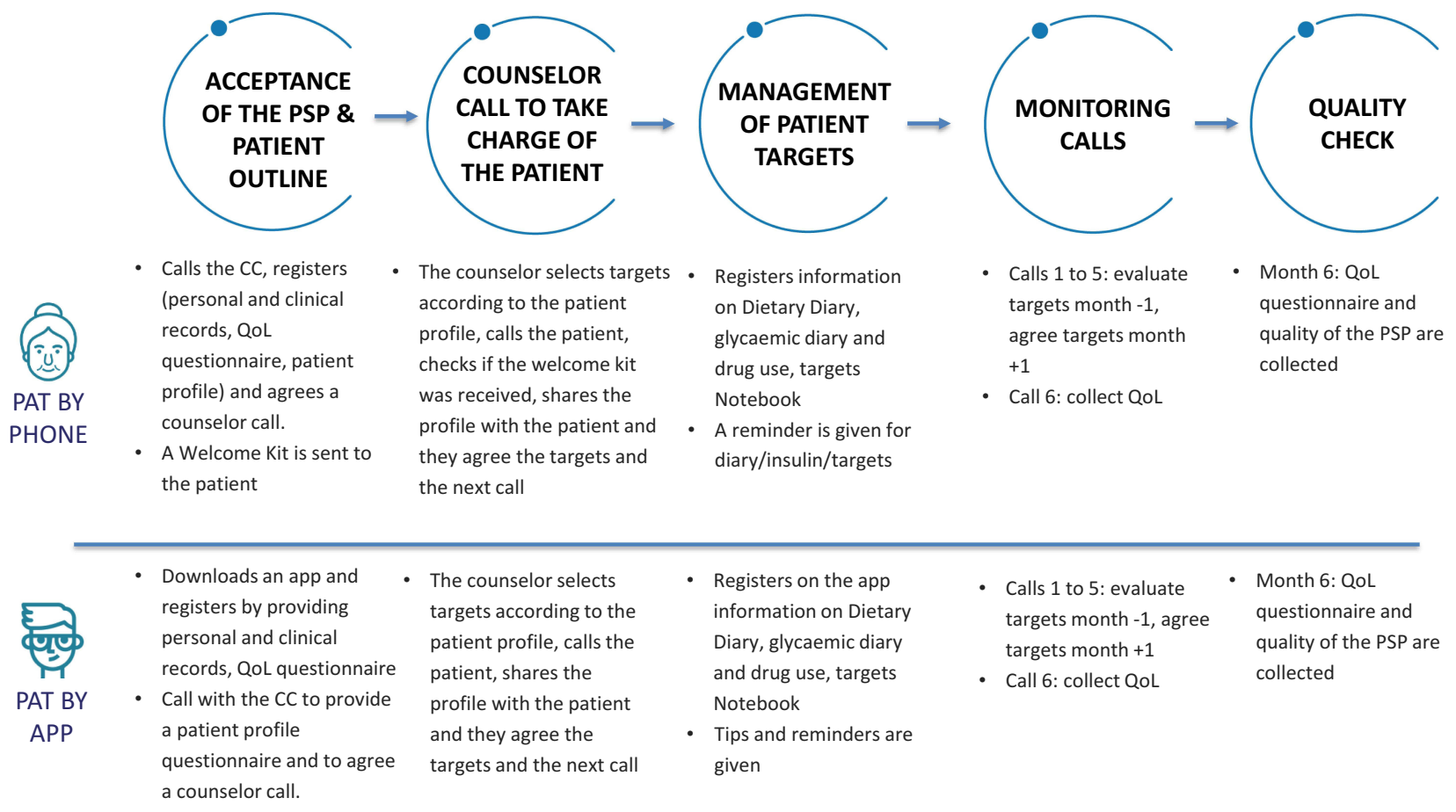

CC: Contact Center; QoL: Quality of Life (PAID-5).

Figure I Flow-chart of the PSP process in the BETHCARE project - Italy, 2020.

of the program (week 1) were performed by using the paired $t$-test or the corresponding Wilcoxon signed-rank test, after checking whether data were normally distributed (based on the Shapiro-Wilk statistic). Two-sided p-values $<0.05$ were identified as statistically significant, but were only considered as exploratory results. All analyses were conducted using SAS version 9.4 (Cary, NC, USA).

\section{Results}

Table 1 shows the main socio-demographic characteristics of subjects enrolled in the project. The median age at enrolment was 57 years ( $\mathrm{IQR}=15.2$ ), with $17 \%$ of subjects aged 70 years or more. Fifty-eight percent of subjects were males, and the majority of patients lived in southern (44\%) or northern (40\%) Italy. Education degree was primary school for $19 \%$, secondary school for $41 \%$, high-school degree for $33 \%$ and university degree for $6 \%$ of subjects. Mean body mass index at baseline was 30.2 ( $\mathrm{SD}=7.5$; median=28.8) $\mathrm{kg} / \mathrm{m}^{2}$, with $41 \%$ of patients reporting a BMI above the WHO obesity threshold of $30 \mathrm{~kg} / \mathrm{m}^{2}$.

Self-reported clinical and other disease-related characteristics of patients are given in Table 2. Most subjects had type II diabetes (89\%) and used concomitant drug treatment for non-diabetic conditions (86\%). Thirty-eight patients reported HbAlc above $8.5 \%$, and $34 \%$ reported a short duration of insulin treatment of less than one year. With reference to diabetes control in the year before enrolment in the project, $43 \%$ of patients self-reported at least one episode of hypoglycaemia and $8 \%$ reported hospitalization due to diabetes.

Table 3 gives general information on contacts between counselors and patients during the PSP. The first call of counselors, aimed to take the patient in charge and to agree the objectives, had a duration on average of 25.0 minutes $(\mathrm{SD}=12.6)$. A total of 220 monitoring calls were performed during follow-up, with a mean of 3.5 calls per patient $(\mathrm{SD}=1.7)$ and an average duration of 18.2 minutes $(\mathrm{SD}=8.3)$. The median duration of follow-up was 131 days (25-75\% percentiles: $58-156$ days).

Table 4 reports information on patient satisfaction at the end of program, separately for those participating by telephone contacts and by mobile app. Fifty-eight out of 63 subjects $(92 \%)$ chose to participate through telephone contacts and $5(8 \%)$ by app. Most participants evaluated counselors' calls "useful" or "very useful" (91\% of telephone participants, $100 \%$ of app users), duration of calls 
Table I Socio-Demographic Characteristics of 63 Subjects Enrolled in the BETHCARE Project - Italy 2020

\begin{tabular}{|c|c|}
\hline & $\mathbf{N}(\%)$ \\
\hline \multicolumn{2}{|l|}{$\operatorname{Sex}^{\mathrm{a}}$} \\
\hline Female & $26(41.9)$ \\
\hline Male & $36(58.1)$ \\
\hline \multicolumn{2}{|l|}{ Age } \\
\hline$<50$ & $16(25.4)$ \\
\hline $50-59$ & $24(38.1)$ \\
\hline $60-69$ & $12(19.0)$ \\
\hline$\geq 70$ & II (17.5) \\
\hline Mean (SD) & $58.9(12.7)$ \\
\hline Median (IQR) & $57.0(15.2)$ \\
\hline \multicolumn{2}{|l|}{ Area of Italy } \\
\hline North & 25 (39.7) \\
\hline Centre & $10(15.9)$ \\
\hline South/Isles & $28(44.4)$ \\
\hline \multicolumn{2}{|l|}{ Education } \\
\hline Primary school & $12(19.0)$ \\
\hline Secondary school & $26(4 I .3)$ \\
\hline High school & $21(33.3)$ \\
\hline University degree & $4(6.3)$ \\
\hline \multicolumn{2}{|c|}{ Body mass index $\left(\mathrm{kg} / \mathrm{m}^{2}\right)$} \\
\hline$<25$ & $16(25.4)$ \\
\hline $25-<30$ & $21(33.3)$ \\
\hline$\geq 30$ & $26(4 I .3)$ \\
\hline Mean (SD) & $30.2(7.5)$ \\
\hline Median (IQR) & $28.8(8.9)$ \\
\hline
\end{tabular}

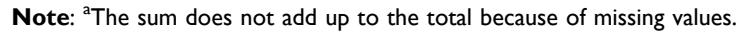
Abbreviations: IQR, interquartile range; SD, standard deviation.

"adequate" or "adequately long" (98\% by telephone, $80 \%$ by app), were satisfied with the educational pathway of the PSP ( $88 \%$ by telephone, $100 \%$ by app) and declared to be more confident in diabetes management $(93 \%$ by telephone, $80 \%$ by app). About half of the participants were confident to maintain their targets after the end of the program ( $50 \%$ by telephone, $40 \%$ by app).

Figure 2 shows the achievement of emotional (Panel A), physical (Panel B) and nutritional (Panel C) targets
Table 2 Selected Self-Reported Disease-Related Characteristics of 63 Subjects Enrolled in the BETHCARE Project - Italy, 2020

\begin{tabular}{|c|c|}
\hline & $\mathbf{N}(\%)$ \\
\hline \multicolumn{2}{|l|}{ Diabetes type } \\
\hline Type I & $7(11.1)$ \\
\hline Type II & $56(88.9)$ \\
\hline \multicolumn{2}{|l|}{ HbAla ${ }^{a}$} \\
\hline Below $7.5 \%$ & $12(25.5)$ \\
\hline $7.5 \%$ to $8.5 \%$ & $16(34.0)$ \\
\hline Above $8.5 \%$ & $18(38.3)$ \\
\hline \multicolumn{2}{|c|}{ Duration of insulin therapy ${ }^{a}$} \\
\hline Less than I year & $21(34.4)$ \\
\hline I to 3 years & $10(16.4)$ \\
\hline 3 to 5 years & $10(16.4)$ \\
\hline 5 to 10 years & $8(13.1)$ \\
\hline More than 10 years & $12(19.7)$ \\
\hline \multicolumn{2}{|c|}{ Self-reported hypoglycemia during last year } \\
\hline No & $36(57.1)$ \\
\hline Yes & $27(42.9)$ \\
\hline \multicolumn{2}{|c|}{ Hospitalization for diabetes during last year } \\
\hline No & $58(92.1)$ \\
\hline Yes & $5(7.9)$ \\
\hline \multicolumn{2}{|c|}{ Concomitant use of other (non-diabetes) drugs } \\
\hline No & $9(14.3)$ \\
\hline Yes & $54(85.7)$ \\
\hline
\end{tabular}

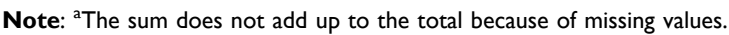

after 1, 8 and 16 weeks of the program in 34 patients with at least 16 weeks of follow-up. No variations in the achievement of emotional objectives emerged during the program, with mean scores of 1.56 at week $1,1.53$ at week 8 and 1.53 at week 16 (p-value $=0.96$ ). The mean score for achievement of physical targets was low at weeks 1 and 8 (equal to 1.09 and 0.94 , respectively), increasing to 1.35 at week 16 (p-value $=0.15$ ). Achievement of nutritional targets improved during counseling, from a mean score of 1.56 at week 1 to 1.88 at week 16 (p-value $=0.03$ ). When all 63 participants were examined, the latter results were materially unchanged (scores of 1.57 and 1.88 at weeks 1 and 16 , respectively). 
Table 3 General Information on Patient Counselling Contacts in the BETHCARE Project - Italy, 2020

\begin{tabular}{|l|c|}
\hline Information & Results \\
\hline Duration of first (taking charge) call (minutes) \\
\hline Mean (SD) & 25.0 (I2.6) \\
\hline Median (percentiles 25 to 75) & 21.9 (I5.3-3I.2) \\
\hline No. of monitoring calls per subject \\
\hline Mean (SD) & 3.5 (I.7) \\
\hline Median (percentiles 25 to 75) & 4 (2 to 5) \\
\hline Duration of monitoring calls (minutes) \\
\hline Mean (SD) & 18.2 (8.3) \\
\hline Median (percentiles 25 to 75) & 15.8 (II.6-23.3) \\
\hline Duration of patient follow-up (days) \\
\hline Median (percentiles 25 to 75) & 131 (58 to I56) \\
\hline
\end{tabular}

Abbreviation: SD, standard deviation.

Figure 3 shows the variation of mean body weight during the program in 33 patients with at least 16 weeks of follow-up and complete anthropometric data. At week 1, mean body weight was $84.9 \mathrm{~kg}$. This decreased to $84.3 \mathrm{~kg}$ at week 4 and then showed small variations ranging between a minimum mean of $84.0 \mathrm{~kg}$ (week 10) and a maximum mean of $84.4 \mathrm{~kg}$ (week 8). At week 16, the mean body weight was $84.2 \mathrm{~kg}$ (p-value $=0.11$ as compared to week 1). PAID-5 mean score decreased from 8.34 at baseline to 7.57 at the end of the program (data not shown), with a mean change of -0.78 ( $\mathrm{p}$-value $=0.32$ ).

\section{Discussion}

This project conducted during the challenging period of COVID-19 pandemic reported a successful participation to a PSP in diabetes care and favorable patient satisfaction at the end of the program. Achievement of nutritional targets increased during the program, indicating a favorable role of patient counseling in the management of everyday lifestyle in this chronic disease. Notwithstanding the stressful time-frame - ie, most patients participated during the first national lockdown in Spring or during the second COVID19 outbreak in Autumn 2020, with several studies showing the high distress experienced by patients with chronic diseases, elderly and other risk groups during the

Table 4 Participation Type and Satisfaction with Counselling at the End of the Program in the BETHCARE Project - Italy, 2020

\begin{tabular}{|c|c|c|}
\hline & Participation by Telephone $(n=58)$ & Participation by App $(n=5)$ \\
\hline & $\mathrm{N}(\%)$ & $\mathrm{N}(\%)$ \\
\hline \multicolumn{3}{|c|}{ Why did you choose to participate by telephone? ${ }^{\mathrm{a}}$} \\
\hline I prefer to talk to a person & $47(82.5)$ & - \\
\hline Not informed on the App & $6(10.5)$ & - \\
\hline Other & $4(7.0)$ & - \\
\hline \multicolumn{3}{|c|}{ Would you select again the same participation method? ${ }^{\mathrm{a}}$} \\
\hline No & $6(10.5)$ & $0(0.0)$ \\
\hline Yes & $39(68.4)$ & $2(66.7)$ \\
\hline Do not know & $12(21.1)$ & I (33.3) \\
\hline \multicolumn{3}{|c|}{ Ease of the participation procedure ${ }^{a}$} \\
\hline Very easy & $15(25.9)$ & I $(25.0)$ \\
\hline Easy & $34(58.6)$ & $0(0.0)$ \\
\hline Fairly easy & $0(0.0)$ & $3(75.0)$ \\
\hline Not easy nor difficult & $8(13.8)$ & $0(0.0)$ \\
\hline Difficult & I (I.7) & $0(0.0)$ \\
\hline
\end{tabular}

(Continued) 
Table 4 (Continued).

\begin{tabular}{|c|c|c|}
\hline & Participation by Telephone $(n=58)$ & Participation by App $(n=5)$ \\
\hline \multicolumn{3}{|l|}{ Usefulness of counselor's calls } \\
\hline Very useful & $20(34.5)$ & I (20.0) \\
\hline Useful & $33(56.9)$ & $4(80.0)$ \\
\hline Not useful nor useless & $4(6.9)$ & $0(0.0)$ \\
\hline Little useful & $\mathrm{I}(\mathrm{I} .7)$ & $0(0.0)$ \\
\hline \multicolumn{3}{|l|}{ Duration of counselor's calls } \\
\hline Adequate/adequately long & $57(98.3)$ & $4(80.0)$ \\
\hline Too short/a bit short & $\mathrm{I}(\mathrm{I} .7)$ & I (20.0) \\
\hline \multicolumn{3}{|l|}{ Are you satisfied with the educational path of the program? } \\
\hline Yes, I would like to continue with it & $24(4 \mid .4)$ & I (20.0) \\
\hline Yes, I would suggest it to a friend/relative with the same disease & $27(46.5)$ & $4(80.0)$ \\
\hline Not satisfied nor dissatisfied & $7(12.1)$ & $0(0.0)$ \\
\hline \multicolumn{3}{|c|}{ After this program, do you feel your relation with the Clinical Centre has changed? } \\
\hline No & $54(94.7)$ & $5(100.0)$ \\
\hline Yes & $3(5.3)$ & $0(0.0)$ \\
\hline \multicolumn{3}{|l|}{ Do you feel more confident in diabetes management? } \\
\hline No & $4(6.9)$ & I (20.0) \\
\hline Yes & $54(93.1)$ & $4(80.0)$ \\
\hline \multicolumn{3}{|c|}{ Now that the program has ended, do you think you will be able to maintain your target by yourself? } \\
\hline No, it was difficult even with counselling & $5(8.6)$ & $0(0.0)$ \\
\hline I hope so, but it will not be easy & $22(37.9)$ & $3(60.0)$ \\
\hline Yes, I feel very motivated & $29(50.0)$ & $2(40.0)$ \\
\hline Do not know & $2(3.5)$ & $0(0.0)$ \\
\hline
\end{tabular}

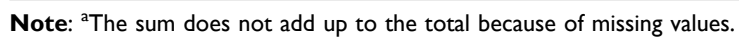

pandemic $^{12-14}$ - the mean weight of enrolled diabetes patients tended to decrease during the first month of counseling, and to level off subsequently. In a recent survey on dietary habits and changes during the COVID-19 lockdown in Italy, a large portion of subjects reported positive weight modification, as well as physical activity reduction for nearly $70 \%$ of responders. ${ }^{15}$

Several studies were conducted to assess whether telephone coaching effectively improved health outcomes in patients with diabetes. However, most programs were conducted in patients with type 1 disease, whereas evidences for type 2 diabetes are still relatively limited. In a randomized controlled trial of patients with type 2 diabetes, Pro-Active Call Center Treatment Support (PACCTS) facilitated improvements in glycemic control. ${ }^{8}$ This was also well-accepted by users, who considered it a satisfactory service that made them more knowledgeable and more confident in their ability to manage and control their diabetes and general well-being. ${ }^{16}$ Other evidence comes from the Get Healthy Information and Coaching Service (GHS), an effective 6-month healthy lifestyle coaching service including a specific prevention module focused on subjects at increased risk of type 2 diabetes. ${ }^{17}$ This showed that a telephone-delivered program may be 


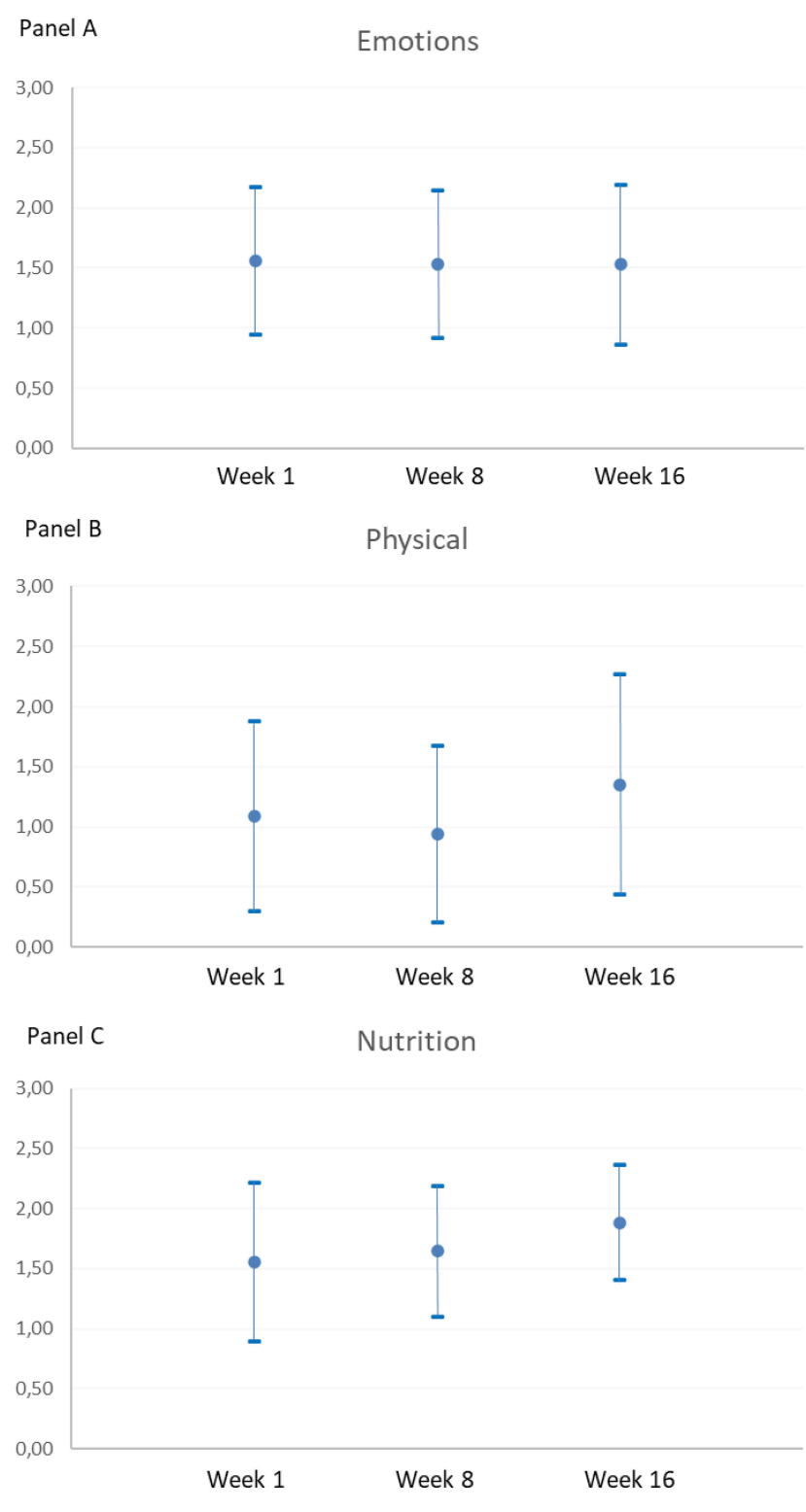

Figure 2 Achievement of emotional (A), physical (B) and nutritional (C) targets during counselling in 34 subjects with at least 16 weeks of follow-up, BETHCARE project - Italy, 2020.

Notes: For each target, a higher score indicates a better achievement (ie, $0=$ Target not achieved at all; 3= Target was fully achieved). Mean scores and their SD are reported.

beneficial in promoting weight reduction and improvements towards healthy lifestyle behaviors. These results were comparable with other diabetes prevention lifestyle programs, indicating that telephone coaching may be a suitable intervention. Furthermore, in a recent community-based, randomized, controlled trial, 365 adults with type 2 diabetes mellitus were assigned to either usual diabetes education $(n=177)$ or diabetes health coaching $(n=188)$ plus diabetes education intervention to evaluate changes in $\mathrm{A} 1 \mathrm{C}$ after 1 year and, as secondary outcomes, the evolution of quality of life scores and self-care behaviours. Diabetes health coaching plus diabetes education reduced $\mathrm{A} 1 \mathrm{C}$ by $0.49 \%$ more than diabetes education alone and improved quality of life scores. ${ }^{18}$ In line with previous randomized studies, ${ }^{19,20}$ our project provides additional information on the feasibility and effectiveness of PSP in type 2 diabetes, in a Real-World setting.

There are several different ways to provide support to patients. New technologies and way to think traditional PSP may offer effective and more convenient alternatives to manage diabetic patients. Indeed, telemedicine is an effective and well accepted means of providing diabetes education to patients. ${ }^{21}$ Also, digital-based programs combined with human coaching were found to decrease chronic disease risk. ${ }^{22}$ Digital Health technology has developed rapidly, and health apps have become increasingly common in diabetes care and self-management. Overall, mobile phone applications may be a useful tool for improving self-management and perceptions of selfefficacy in people suffering from diabetes. ${ }^{23}$ Furthermore, telemedicine had a key role to assist diabetic patients during the COVID-19 pandemic, especially in lockdown periods. ${ }^{24,25}$ In the present project, provided that counseling was given to all participants by telephone calls, patients were given the opportunity to choose between a health app or a traditional approach (based on telephone contacts and a kit of materials) for their registration, data collection and final questionnaire. More than $90 \%$ of subjects, however, decided to participate through telephone, mainly because they preferred to interact with a person. The generally low educational status of participants, their relatively high age and the concomitant COVID-19 pandemic may, at least in part, explain the preference towards telephone. Telephone contact could, in fact, prevent patients from feeling alone in dealing with their disease during this challenging period. The large preference directed to telephone contact is in any case in line with previous concerns expressed on barriers to overcome for the use of health apps in education programs and self-management of chronic diseases, including poor usability resulting from technological issues, inadequate internet access, lack of awareness and health literacy issues. ${ }^{10,23,26}$

An important limitation of this project is its small sample size. However, this was a pilot phase aimed at evaluating the feasibility of the PSP in an Italian multicentric project. In this context, in order to improve the PSP, we carefully considered the reasons of patients who 


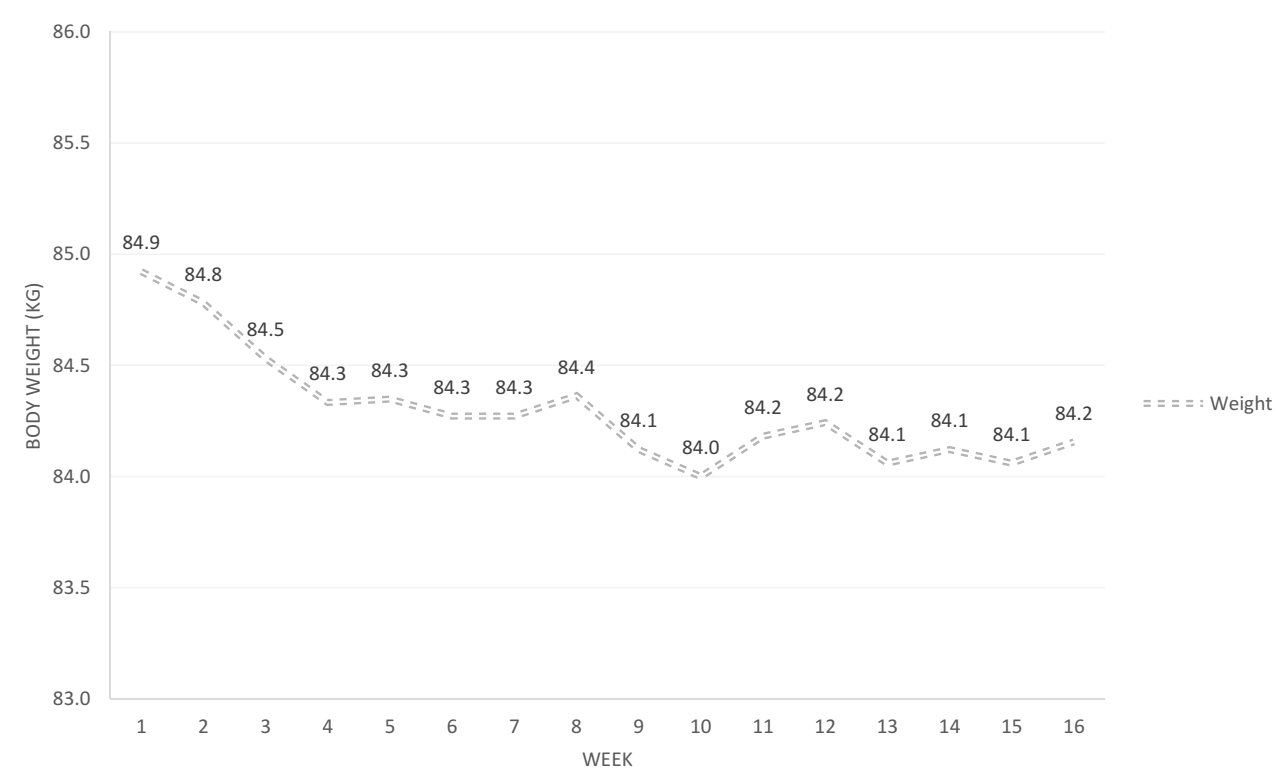

Figure 3 Variation of mean body weight during counselling in 33 subjects with at least 16 weeks of follow-up ${ }^{a}$, BETHCARE project - Italy 2020 . Note: ${ }^{a}$ One patient had several missing data on body weight during follow-up and was thus excluded.

left the program early or were not fully satisfied with the educational pathway, and we identified two main groups of subjects: i) those who were already adequately informed on diabetes and its management, and thus considered the program not particularly useful; ii) those who reported that, during the program, diabetes was a less important problem as compared to other urgent health issues (mainly the COVID-19 pandemic). These aspects will be kept in due consideration in the future. Among other limitations, the uneven distribution of subjects choosing to participate by app vs telephone contact did not allow meaningful comparisons of program feasibility and patient satisfaction between groups. The observational nature of the project implies a lack of randomization of subjects and the possible occurrence of selection and information bias. Still, Real-World projects are important to confirm in a reallife setting (effectiveness) the results previously obtained in RCTs on the efficacy of interventions. Strengths of the program are its nationwide setting (with centers participating in northern, central and southern Italy) and the focus on type 2 diabetes, for which PSP are relatively infrequent.

\section{Conclusion}

This project demonstrated the feasibility and patient appreciation of managing a PSP in diabetes care via telephone, which is particularly important for a chronic disease of the elderly, especially for patients on insulin therapy, and during a pandemic period when face-to-face counseling is problematic.

\section{Acknowledgments}

We are deeply in debt with all the Nurses of the participating Diabetes Centers, all the Counselors and Psychologists involved in this project. We also thank Dr. Stefania Annese, Dr. Daniela Antenucci, Dr. Lucia Mingolla, Dr. Flaminia Carrone, Dr. Maria Gisella Cavallo, Dr. Margherita Occhipinti, Dr. Mario Manunta, Prof. Lucia Frittita, Dr. Rosario Le Moli, Prof. Concetta Irace, Dr. Sabato Mignano, Dr. Flavia Agata Cimini, Dr. Stefania Bertoli, Dr. Natalino Simioni, Dr. Marco Mirani and Dr. Francesca Faggiano for patients' enrolment, Dr. Emily Donatiello and Dr. Giovanna Pasciuto for their suggestions on the manuscript and Dr. Claudio Pelucchi for assisting with statistical analyses.

\section{Funding}

The present article was supported by funding from Healthcare Network Partners Italy.

\section{Disclosure}

AN received unconditional support from Lilly, Boehringer, Astra Zeneca, Novo Nordisk and Sanofi, outside the submitted work. ACB reports grants from Novo-Nordisk SpA, Lilly Italia SpA, Bayer SA, Pikdare Italia SpA, Alfasigma Italia SpA, Mundipharma Italia SpA; personal fees from Sanofi Italia $\mathrm{SpA}$, Johnson \& Johnson Italia SpA, Boehringer Ingelheim Italia SpA, MSD Italia SpA, Alfasigma SpA, Astra-Zeneca Italia SpA; all outside the submitted work. CS, MF and GB report financial 
relationships with AbbVie Srl, Alnylam Italy Srl, Bayer Italia SpA, BioMarin Pharmaceutical Italia Srl, Chiesi Farmaceutici Spa, CSL Behring Italy Spa, Gilead Sciences Italy Srl, GSK Italy Spa, Insmed Italy Srl, Kyowa Kirin Italia, Novartis Farma Spa, Novo-Nordisk Italy SpA, Roche Italy Spa, Sanofi Italy, Sobi Italy, Pfizer Italy Srl, Takeda Manufacturing Italia Spa, Wellspect Srl; all outside the submitted work. The authors report no other conflicts of interest in this work.

\section{References}

1. Vos T, Lim SS, Abbafati C, et al. Global burden of 369 diseases and injuries in 204 countries and territories, 1990-2019: a systematic analysis for the Global Burden of Disease Study 2019. Lancet. 2020;396(10258):1204-1222.

2. Cho NH, Shaw JE, Karuranga S, et al. IDF Diabetes Atlas: global estimates of diabetes prevalence for 2017 and projections for 2045 . Diabetes Res Clin Pract. 2018;138:271-281. doi:10.1016/j. diabres.2018.02.023

3. Williams R, Karuranga S, Malanda B, et al. Global and regional estimates and projections of diabetes-related health expenditure: results from the International Diabetes Federation Diabetes Atlas, 9th edition. Diabetes Res Clin Pract. 2020;162:108072. doi:10.1016/j.diabres.2020.108072

4. Bommer C, Sagalova V, Heesemann E, et al. Global economic burden of diabetes in adults: projections from 2015 to 2030 . Diabetes Care. 2018;41(5):963-970. doi:10.2337/dc17-1962

5. Farrell K, Wicks MN, Martin JC. Chronic disease self-management improved with enhanced self-efficacy. Clin Nurs Res. 2004;13 (4):289-308. doi:10.1177/1054773804267878

6. NICE. Type 2 Diabetes in Adults: Management. National Institute for Health and Care Excellence (NICE) Guideline no. 28; 2015.

7. Dennis SM, Harris M, Lloyd J, Powell Davies G, Faruqi N, Zwar N. Do people with existing chronic conditions benefit from telephone coaching? A rapid review. Austr Health Rev. 2013;37(3):381-388. doi:10.1071/AH13005

8. Young RJ, Taylor J, Friede T, et al. Pro-active call center treatment support (PACCTS) to improve glucose control in type 2 diabetes: a randomized controlled trial. Diabetes Care. 2005;28(2):278-282. doi:10.2337/diacare.28.2.278

9. Varney JE, Liew D, Weiland TJ, Inder WJ, Jelinek GA. The cost-effectiveness of hospital-based telephone coaching for people with type 2 diabetes: a 10 year modelling analysis. BMC Health Serv Res. 2016;16(1):521. doi:10.1186/s12913-016-1645-6

10. Fleming GA, Petrie JR, Bergenstal RM, Holl RW, Peters AL, Heinemann L. Diabetes digital app technology: benefits, challenges, and recommendations. A consensus report by the European Association for the Study of Diabetes (EASD) and the American Diabetes Association (ADA) Diabetes Technology Working Group. Diabetes Care. 2020;43(1):250-260. doi:10.2337/dci19-0062

11. Ma RCW, Holt RIG. COVID-19 and diabetes. Diabet Med. 2020;37 (5):723-725. doi:10.1111/dme.14300
12. Gorenko JA, Moran C, Flynn M, Dobson K, Konnert C. Social isolation and psychological distress among older adults related to COVID-19: a narrative review of remotely-delivered interventions and recommendations. $J$ Appl Gerontol. 2021;40(1):3-13. doi:10.1177/0733464820958550

13. Kang C, Yang S, Yuan J, Xu L, Zhao X, Yang J. Patients with chronic illness urgently need integrated physical and psychological care during the COVID-19 outbreak. Asian J Psychiatr. 2020;51:102081. doi:10.1016/j.ajp.2020.102081

14. Passanisi S, Pecoraro M, Pira F, et al. Quarantine due to the COVID-19 pandemic from the perspective of pediatric patients with type 1 diabetes: a web-based survey. Front Pediatr. 2020;8:491. doi:10.3389/fped.2020.00491

15. Izzo L, Santonastaso A, Cotticelli G, et al. An Italian survey on dietary habits and changes during the COVID-19 lockdown. Nutrients. 2021;13(4):1197. doi:10.3390/nu13041197

16. Long AF, Gambling T, Young RJ, Taylor J, Mason JM. Acceptability and satisfaction with a telecarer approach to the management of type 2 diabetes. Diabetes Care. 2005;28(2):283-289. doi:10.2337/ diacare.28.2.283

17. Cranney L, O’Hara B, Gale J, Rissel C, Bauman A, Phongsavan P. Telephone based coaching for adults at risk of diabetes: impact of Australia's Get Healthy Service. Transl Behav Med. 2019;9 (6):1178-1185. doi:10.1093/tbm/ibz007

18. Taylor W, Gladman D, Helliwell P, et al. Classification criteria for psoriatic arthritis: development of new criteria from a large international study. Arthritis Rheum. 2006;54(8):2665-2673. doi:10.1002/art.21972

19. Sacco WP, Malone JI, Morrison AD, Friedman A, Wells K. Effect of a brief, regular telephone intervention by paraprofessionals for type 2 diabetes. J Behav Med. 2009;32(4):349-359. doi:10.1007/s10865-0099209-4

20. Mons U, Raum E, Kramer HU, et al. Effectiveness of a supportive telephone counseling intervention in type 2 diabetes patients: randomized controlled study. PLoS One. 2013;8(10):e77954. doi:10.1371/ journal.pone. 0077954

21. Izquierdo RE, Knudson PE, Meyer S, Kearns J, Ploutz-Snyder R, Weinstock RS. A comparison of diabetes education administered through telemedicine versus in person. Diabetes Care. 2003;26 (4):1002-1007. doi:10.2337/diacare.26.4.1002

22. Castro Sweet CM, Chiguluri V, Gumpina R, et al. Outcomes of a digital health program with human coaching for diabetes risk reduction in a medicare population. J Aging Health. 2017;30 (5):692-710. doi:10.1177/0898264316688791

23. Jeffrey B, Bagala M, Creighton A, et al. Mobile phone applications and their use in the self-management of Type 2 Diabetes Mellitus: a qualitative study among app users and non-app users. Diabetol Metab Syndr. 2019;11(1):84. doi:10.1186/s13098-019-0480-4

24. Norgaard K. Telemedicine consultations and diabetes technology during COVID-19. J Diabetes Sci Technol. 2020;14(4):767-768. doi:10.1177/1932296820929378

25. Singh AK, Gupta R, Ghosh A, Misra A. Diabetes in COVID-19: prevalence, pathophysiology, prognosis and practical considerations. Diabetes Metab Syndr. 2020;14(4):303-310. doi:10.1016/j.dsx.2020.04.004

26. Alvarado MM, Kum HC, Gonzalez Coronado K, Foster MJ, Ortega P, Lawley MA. Barriers to remote health interventions for type 2 diabetes: a systematic review and proposed classification scheme. J Med Internet Res. 2017;19(2):e28. doi:10.2196/jmir.6382 


\section{Publish your work in this journal}

Patient Preference and Adherence is an international, peer-reviewed, open access journal that focusing on the growing importance of patient preference and adherence throughout the therapeutic continuum. Patient satisfaction, acceptability, quality of life, compliance, persistence and their role in developing new therapeutic modalities and compounds to optimize clinical outcomes for existing disease

Submit your manuscript here: https://www.dovepress.com/patient-preference-and-adherence-journa states are major areas of interest for the journal. This journal has been accepted for indexing on PubMed Central. The manuscript management system is completely online and includes a very quick and fair peer-review system, which is all easy to use. Visit http:// www.dovepress.com/testimonials.php to read real quotes from published authors. 